\title{
Factory Planning Modules for Knowledge Sharing among Different Locations
}

\author{
Michael F. Zaeh and Wolfgang Wagner \\ Technische Universitaet Muenchen, Institute for Machine Tools and Industrial Management \\ (iwb), Boltzmannstrasse 15, D-85748 Garching, Germany. \\ Email: \{michael.zaeh,wolfgang.wagner\}@iwb.tum.de
}

\begin{abstract}
In order to succeed in close-to-saturated markets, companies must offer services that are tailored to suit their customers' individual needs. This necessitates intensive interaction between the supplier and the customer. In order to produce increasingly individualised products close to customer markets, in comparison with today's production structures, a much larger number of factories will be necessary. The factories are distributed locally and directly in the actual markets and therefore have to be adapted to market-specific conditions. Decentralised knowledge needs to be utilised in order to exploit location-specific potentials, and the experience and knowledge about improvements that have been realised in production processes has to be shared among different locations. The use of preconfigured planning modules makes it possible to plan and re-plan factories relatively quickly on the one hand and facilitates reliable planning on the other hand. Digital tools and interactive input media support participatory planning and promote the documentation of knowledge as well as the transfer of knowledge among different locations.
\end{abstract}

Keywords: Individualised products, Close-to-Market production, Factory planning modules, Media for interactive planning

\section{INTRODUCTION}

The current situation of most production companies is characterised by increasing pressure from global competition. Today's customers are better informed and demanding as well as price-conscious. Along with this, the fast technological progress, due to the development of electronics, for example, 
makes the innovation cycles of mechatronic products shorter. The ability to react quickly to the markets' needs is becoming more and more important for production companies (NOFEN et al. 2003). Due to the globalisation of the markets, companies influence the development, production and sales in worldwide networks. In fast-moving buyers' markets, companies must offer innovative products and services that are tailored to their customers needs, together with short delivery times and moderate prices. Companies frequently react to this situation by designing products that are composed of prefabricated components that can be combined to form different product variants. In order to improve customer orientation, companies that are active worldwide perform parts of the product design and development work close to important selling markets of the products. For example the Japanese car manufacturer NISSAN (2004) developed the design for a new car for the European market near Munich in Germany. In some cases, not only the development but also the production operates according to market demands. Simplifying logistics or realising short delivery times by reducing transport times and waiting times are the major motivations here. Thus, in addition to improved interaction, the customer benefits from shorter delivery times and an improved observance of schedules (MILBERG 1996) due to production close to the market. When the added value is produced close to the market, market entry barriers such as local content regulations or sales taxes for imported products can be avoided. Considering that duties and import taxes can be up to 245 per cent of the price, of imported cars for example (RAUCH 1997), production can be economical if it is close to the market.

However, the efforts of companies to improve customer loyalty by offering more product variants and increasing customer orientation can bring about disadvantages as well. It is often difficult for a customer to overlook the enormous number of product variants available on the market. As the products have been developed for an average demand of a specific market, they do not necessarily correspond to a customer's needs. Due to the complexity of technical products, customers are frequently forced to buy features they do not need. On the other hand, production companies risk developing products and product features which are not well received in the customer markets while the production of numerous product variants makes production workflows and logistics complex at the same time.

An effective competitive advantage can be achieved if it is possible to offer specific products to customers. In the case of sophisticated technical products, there are many degrees of freedom by which customer requirements may differ. With today's product development methods, production processes and distribution channels, the augmented customer orientation is hardly realisable. 
Replacing standard products or standardised product variants with individualised technical goods and individualised services has different effects on the product creation process. Among other things, it requires new strategies for interaction with the customer, methods for product adaptation, procedures for factory and production planning and new production techniques for manufacturing materials such as metals or plastics to individual customers' wishes in an economical way.

The Collaborative Research Centre 582 "Production of Individualized Products Close to the Market" is a cross-faculty project in which researchers from different disciplines such as product development, factory planning, and development of production techniques work together to establish innovative approaches, so that customers can obtain individualised products under comparable conditions of series production. The intention to offer products that can be individualised to customer wishes and to produce these goods directly in the markets influences factory planning to a considerable degree.

\section{INDIVIDUALISATION AND CLOSE-TO- MARKET PRODUCTION}

\subsection{Technological Preconditions}

Preliminary production of anything other than basic technical components is almost unthinkable in the case of far-reaching individualisation, since the customer's requirements cannot be reliably predicted. The production of personalised product components, where the customer can designate the form, functions and material, can only begin following product adaptation in line with customer wishes (Figure 1; KRESS 2000). This is not possible in an economical way using conventional production processes, because the cost of developing and building tools or the effort to set up machines would only affect one part. Classical economies of scale can not be achieved, so other potentials of cost reduction have to be made accessible. Therefore production processes are required that specially focus on production with "batch size one".

Processes such as sheet metal forming by computer-controlled drifting or rapid manufacturing of individual components, which allow the manufacturing of metal or plastic parts using tools that are not attached to the specific geometry of a part, are developed in different sub-projects of the Collaborative Research Centre 582. As the economies of scale are reduced, other potentials of cost reduction, such as economies of learning, are required (PILLER 2001), that depend on the number of executions of production 
processes and the complexity of the process rather than the number of identical parts produced. Economies of scope are based upon the use of production resources for manufacturing more than one product type. These economies offer potential especially when the new production processes are applied: different parts can be manufactured, but they do not require the typical setup efforts. This contributes to benefiting from capacities of the resources which might eventually be unused when focusing on one-productmanufacturing. Economies of integration characterise the combination of economies of scope and economies of scale. Both of them aim to cover the cost of resources by augmented production output.
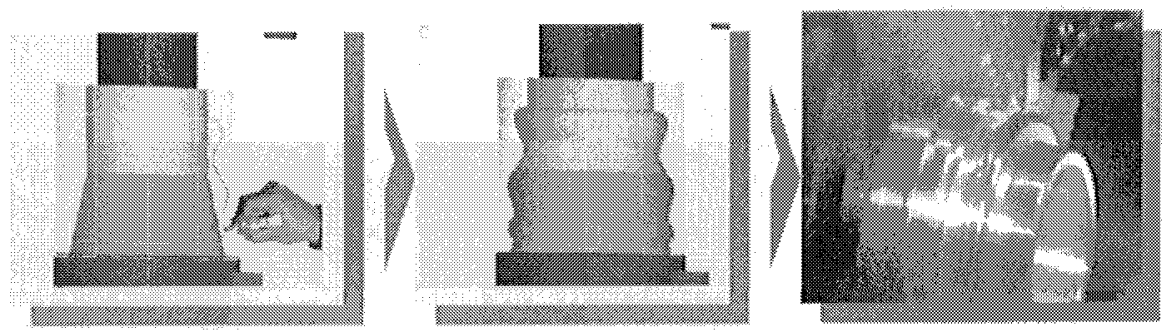

Figure 1: Manufacture of individualised parts

The manufacture of individualised products therefore requires standardised processes that can be used in the same form independently of the distinctness of the individual product.

\subsection{Closeness to Customer Markets}

Product individualisation, which can satisfy customers, is only possible if the supplier can accurately query the customer's wishes. This requires intensive interaction between the supplier and the customer. For this purpose, companies servicing world markets must go to the customer.

\section{EFFECTS ON FACTORY PLANNING}

Closeness to the customer and close-to-market production are vital factors for successfully manufacturing personalised products. Compared with today's production structures, a much larger number of close-to-market factories will be necessary in order to meet these requirements. These so called mini-factories can be described as units comprising sales, design and production (REINHART et al. 2000). Mini-factories develop and generate customised goods close to customer markets. Customers have the possibility to 
individualise their products. The adaptation of individual products to customers' wishes takes place starting from a pre-developed product spectrum. In the mini-factories, customer-specific parts are manufactured and assembled together with order-neutral parts to form a customer-specific technical product.

Close-to-market production of individualised products opens up new potential for companies, but also makes them face new factory planning tasks which have to be dealt with using new methods.

\subsection{Dispersion of the Total Number of Pieces}

As a result of a large number of locally distributed close-to-market minifactories, coupled with shorter innovation cycles for products and production technology, a great effort for frequent production planning and re-planning is to be expected. Another important fact is that mini-factories are distributed locally and directly in the actual markets. Individual factories must therefore be adapted to market-specific conditions. Thus, although mini-factories are similar they also have a distinct location-specific character. However, these individual mini-factories have comparable processes, which is a prerequisite for using knowledge in multiple locations.

Decentralised knowledge must be utilised in order to exploit locationspecific potential. The total number of pieces produced is distributed to different mini-factories. Nevertheless, if production at different locations does not start simultaneously, it should be possible to tap the experience effects of the overall group in the best possible way. Therefore it is necessary to share the experience and the knowledge about improvements that have been realised in production processes among different locations. An attempt must be made to consider as many aspects as possible for the factory to be planned and to optimise these in the planning stages.

\subsection{Factory Modules}

The goal conflict between planning many different variants of mini-factories and reliable, fast and comprehensive planning can be solved by creating groups of subunits. Preconfigured modules with defined interfaces are adapted and can be combined according to the location. This also allows new versions to be developed and integrated. Another advantage of a modular production structure is the possibility to identify affected modules and to isolate adaptations when changes in production become necessary (SCHUH et al. 2003). Functioning subunits should be employed with a view to avoiding optimisation loops, and the optimisation of these subunits should 
make it possible to use and disseminate proven basic knowledge within the company.

Under these conditions, strategies based on construction systems must be adapted to factory planning tasks (REINHART et al. 2000; EVERSHEIM 2001). In factory planning tasks, equal platforms that are suitable for different cases are hardly available. On the one hand, new manufacturing facilities or changes have to be incorporated into existing structures. On the other hand, when planning new projects at different locations in different countries, repetition effects can hardly be achieved: in general, conditions such as legal regulations or the connection to the infrastructure are different. Therefore, having possibilities to effect adaptations is necessary.

When using modular construction systems in the field of product development, for example, a distinction is made between planning construction sets that contain modules that have an equal or different hierarchy (Borowski, 1961). In addition, modules can differ (KOHLHASE 1997) in whether

- their application is required or optional

- they are abstract or concrete (substantial)

- they are elementary or configured modules.

The so-called configured modules are composed of subordinate modules. At the lowest level, there are elementary modules that cannot be configured further. There are different kinds of modularisation that depend on the degrees of freedom for the combination of different modules (PILLER 2001). Planning mini-factory structures requires the so-called individual modularisation to be adapted. The basic principle for this purpose is a common basic architecture (abstract), complemented with a determined or variable number of modules (ULRICH et al. 1991). In the field of process design, modular design integrates operations for processing modules with defined interfaces and associated input and output parameters (AURICH et al. 2003). Process modularisation and concurrent integration of the corresponding information helps to abolish the dissociation of tasks that belong together from the contents (REINHART, GLANDER et al. 2000). With this approach, separate modules and the associated information are planned in advance, although their composition is not.

Single factory modules thus are units with defined interfaces that are able to execute one or several machining steps for the product (Figure 2). They have input and output parameters for the material flow. These input and output parameters are created and required by upstream and downstream modules. The structure of factory modules corresponds to the form of configured modules and allows location-specific adaptations. These configured modules consist of elementary modules that can not be modified further. The ele- 
mentary modules contain the components of the manufacturing facilities that ensure the quality of the production.

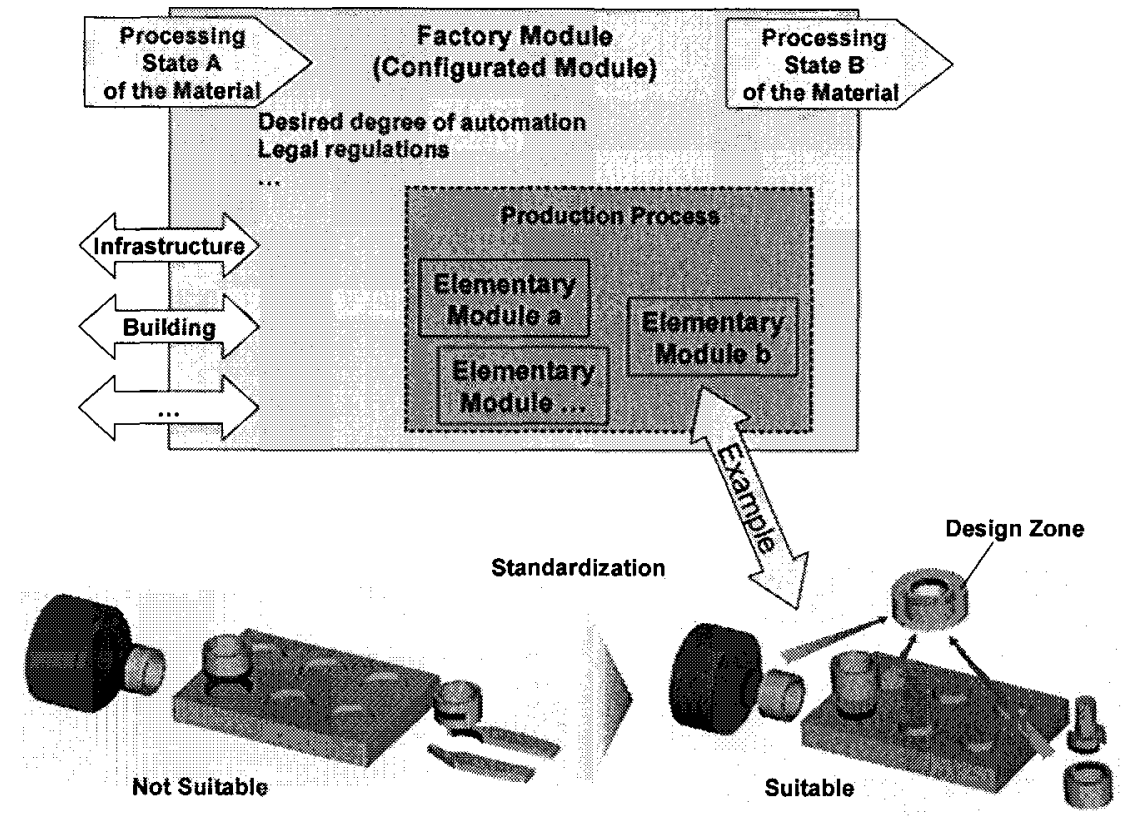

Figure 2: Configured and elementary modules

Figure 2 shows an example of standardised production utilities: due to appropriate design, the devices for manufacturing, transporting and handling individual product components are constructed in a way so that they fit product areas in which the customer is not interested. They are independent of the design zone that can be adapted to individual customer wishes, for example the exterior shell (KRESS 2000). As these devices can be applied without major adaptations, not every new alignment of the production will cause efforts, for example, to develop and build the production utilities. Planning, manufacturing and setting up appropriate production utilities take a large share of time in projects (RONG et al. 2003). Components that need not be developed for specific use cases, for example reusable, product-neutral apparatuses, are cost-saving and quickly available (COMSTOCK et al. 2000). This is also a precondition for manufacturing large numbers of unique items using industrial processes and mastering production time and costs at the same time. 


\subsection{Factory Planning Modules}

When aiming to develop many mini-factories that are comparable but can be adapted to different locations, it is worthwhile to develop structures for a construction set for factory planning. This construction set contains configured modules. These include preconfigured structuring solutions (REINHART et al. 2000). The required modules must be characterised for the different kinds of production processes and resources required by the company. When planning a factory, these preconfigured components are selected and adapted for a specific planning project. Thus mini-factories possess a common basic structure with specifically adapted sub-units. Due to the modular structure of the factories, comparable formations can be found at different locations. Production processes in the globally located mini-factories correspond to the same standards. This supports the application of experience acquired at other locations. Optimisation procedures occurring during operation must therefore be incorporated in the planning to ensure that the building block system is enriched with information. In such cases, the effects of learning must be realised by the repeated and comparable execution of processes. The knowledge about processes has to be documented and reused like a "platform" (EVERSHEIM, SCHUH 2003).

\section{IMPLEMENTATION AND TOOLS}

Adaptations of factories must be planned as accurately as possible in order to allow the factories to operate at the most economical operating point. The large number of factories requires planning scenarios to be generated promptly, i.e. short-term fluctuations in demand must permit fast replanning and adaptation that cost little time and effort. These updates are frequently unsuccessful due to the heterogeneity of planning and consequently give rise to redundant data. In planning tasks only a minor part of the time is needed for decisions, whereas a major part is needed to gather, edit and document information (YOUNIS et al. 1997). Planning support should be provided for this reason.

Concerning factory planning, important requirements are the ability to change planning scenarios quickly, the possibility for distribution and dissemination of information among different departments and locations, and the ability to handle large quantities of information. High-performance digital planning tools are a prerequisite for this. The introduction of tools for the so-called "digital factory" or "virtual production" (REINHART et al. 2003) is expected to reduce planning times by up to $40 \%$. Around $80 \%$ of this progress can be traced back to the development of appropriate methods and 
new work procedures (REINFELDER et al. 2003; HALLER et al. 2002). The objective is to plan as thoroughly as possible and to facilitate planning procedures using the concept of factory modularisation and planning modularisation. For the purposes of the application of close-to-market mini-factories, tools must be specifically configured so that the planning method with preconfigured modules can be realised using the tools of the digital factory. The relations between planning objects and their properties such as occur in the integrated planning of factory structures are complex. They generally change during the planning and development phase and must be updated during operation. A primary goal is therefore to design the planning tools so that integrated planning with intuitive media is supported, which facilitates module handling. Planning with interactive input fields and simultaneous 3D visualisation has proven promising for planning factory layouts (WESTKÄMPER et al. 2001; WIRTH et al. 2001). The basic idea of these input media is for a group of planners and skilled workers to discuss layout changes together and enter these via touch-sensitive or imaging screens. Explicit as well as implicit knowledge (NONAKA et al. 1995) can enter into this process and is documented. Similar input media should be used to handle complex planning modules ( $\mathrm{ZAEH}$ et al. 2003). Adaptations that are incorporated in the layout are assessed in a 3D display. The tool for layout planning is coupled to a process planning tool. Therefore changes can be updated immediately in a process planning database which is the basis for data-integration in process planning (Figure 3 ).
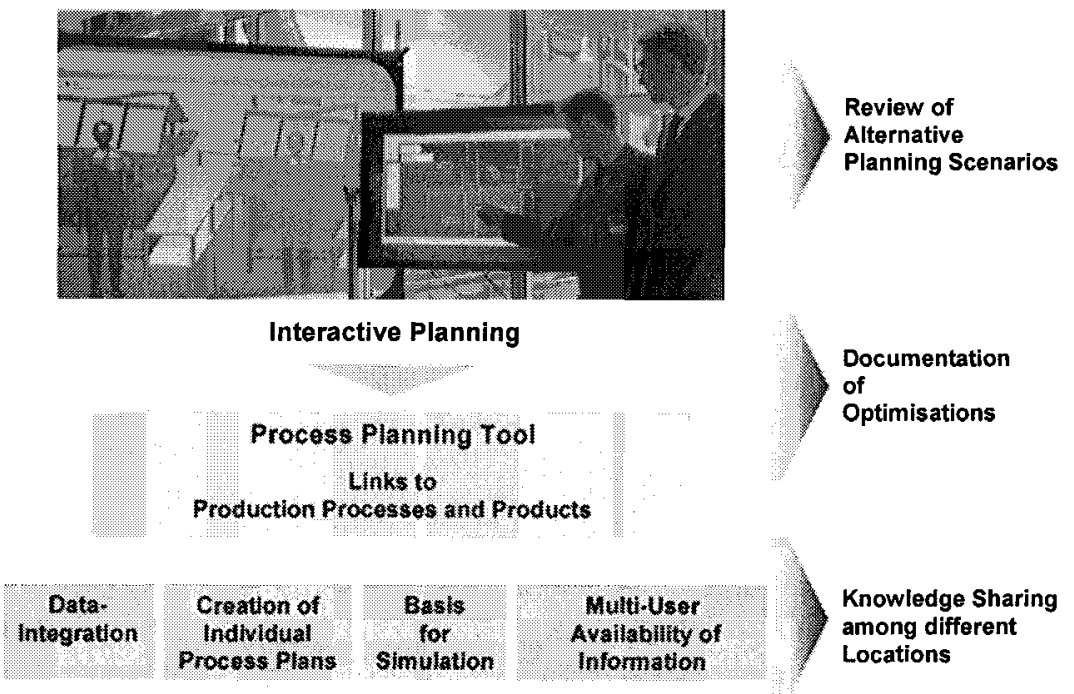

Figure 3: Media for interactive planning 


\section{BENEFIT}

The application of preconfigured factory planning modules and the usage of standardised production resources causes mini-factories to have a common basic structure with sub-units that are adapted to specific locations. This facilitates the transfer of optimisations. Further improvements, at other locations for example, need to be acquired from the actual situation (KARLSSON et al. 2003). This is only possible if the knowledge of optimisations is available. Based on the demonstrated planning procedures that are backed up by interactive media, optimisations are documented and can be shared among different locations. The production processes in the globally distributed mini-factories correspond to the same standards, and it therefore becomes possible not only to exchange experience but also tools or production facilities. For a comparable global process standardisation, the Honda company has calculated that the investments in factories for production starts can be halved in the future (SHIPLETT 2003).

The use of modularised planning makes it possible to reduce the efforts for factory planning and accelerates the planning process. Optimisations that flow back into the modules allow experiences gained during production to be incorporated in the knowledge base, thus helping companies to manufacture the products requested by the customer quickly and cost-effectively. This permits fast and economical planning of close-to-market factories.

\section{ACKNOWLEDGEMENTS}

The Collaborative Research Centre SFB 582 "Production of Individualised Products Close to the Market" is funded by the German Research Foundation (Deutsche Forschungsgemeinschaft DFG).

\section{REFERENCES}

AURICH, J. C.; BARBIAN, P.; WAGENKNECHT, C.:

Prozessmodule zur Gestaltung flexibilitätsgerechter Produktionssysteme.

In: ZWF Zeitschrift für wirtschaftlichen Fabrikbetrieb,

München, 98(2003)5, pp. 214-218.

BOROWSKI, K.-H.:

Das Baukastensystem in der Technik.

Berlin: Springer 1961. 
COMSTOCK, M; OSSBAHR, G.:

Hyper-Flexibility - A Concept for a New Dimension in System Variability.

In: The manufacturing system in its human context - a tool to extend the global welfare.

Stockholm: CIRP College International pour l'Etude Scientifique des Techniques de

Production Mecanique, 2000, pp. 372-377.

(Proceedings of 33rd CIRP International Seminar on Manufacturing Systems)

EVERSHEIM, W.:

Die Einmalaufgabe mausert sich zum Dauerprozess.

In: Industrieanzeiger

Leinfelden-Echterdingen et al., 123(2001)40, pp. 76.

EVERSHEIM, W.; SCHUH, G.:

Standard, individualisiert - individuell.

In: Marktchance Individualisierung.

Eds.: REINHART, G.; ZÄH, M. F.

Berlin: Springer, 2003, pp. 71-77.

HALLER, Eberhard; SCHILLER, Emmerich F.:

Digitale Fabrik bei DaimlerChrysler - Herausforderungen und Chancen.

In: Automobil Forum Ludwigsburg,

Landsberg, 2002, pp. 2/1-2/9.

KARLSSON, T.; OSCARSON, J.:

Information Transfer for Virtual Manufacturing Systems.

In: Progress in virtual manufacturing systems.

Ed.: BLEY, Helmut.

Saarbrücken: CIRP College International pour l'Etude Scientifique des Techniques de

Production Mecanique, 2003, pp. 131-136.

(Proceedings of 36rd CIRP International Seminar on Manufacturing Systems)

KOHLHASE, N.:

Strukturieren und Beurteilen von Baukastensystemen. Strategien, Methoden, Instrumente.

Süsseldorf: Verein Deutscher Ingenieure, 1997.

KRESS, M.:

Maßgeschneidert auf virtueller Basis.

In: Die Neue Fabrik 2000, Produktion im Wandel.

Landsberg: Moderne Industrie, 2000, pp. 28-29.

MILBERG, J.:

Montieren wo die Märkte sind.

13. Deutscher Montagekongreß.

Landsberg: Moderne Industrie, 1996.

NISSAN:

http://www.nissan.co.at/AKTUELL/NEWS/2001/24_Sunderland.html, 09.02.2004

NOFEN, D.; KLUSSMANN, J.; LOELLMANN, F.:

Transformability by Modular Facility Structures.

In: Proceedings of the CIRP 2nd International Conference on Reconfigurable

Manufacturing.

Ann Arbor, MI: University of Michigan College of Engineering, 2003.

NONAKA, I.; TAKEUCHI, H.:

The Knowledge Creating Company.

New York, NY: Oxford University Press, 1995. 
PILLER, Frank T.:

Mass Customization.

Wiesbaden: Gabler Verlag, 2001.

RAUCH, M.:

Aufschwung am Nil,

In: BMW Magazin,

München, (1997)4, pp. 84-85.

REINFELDER, Anton; KOTZ, Thomas:

40 Prozent weniger Planungszeit.

In: Automobil Produktion,

Landsberg, 16(2002)5, pp. 34-35.

REINHART, Gunther; EFFERT, C.; GRUNWALD, S.; PILLER, F.; WAGNER, W.:

Minifabriken für die marktnahe Produktion.

In: Zeitschrift für wirtschaftlichen Fabrikbetrieb,

München, 95(2000)12, pp. 597-600.

REINHART, G.; HAAG, M.; FUSCH, T.; WAGNER, W.:

Mit der Digitalen Fabrik zur Virtuellen Produktion.

In: Proceedings of Münchener Kolloquium: Grenzen überwinden - Wachstum der neuen

Art.

München: Utz, 2003, pp. 137-158.

RONG, Y.; HAN, X.:

Computer-aided Reconfigurable Fixture Design.

In: Proceedings of the CIRP 2nd International Conference on Reconfigurable

Manufacturing,

Ann Arbor, MI: University of Michigan College of Engineering, 2003.

SCHUH, G.; VAN BRUSSEL, H.; BOËR, C.; VALCKENAERS, P.; SACCO, M.;

BERGHOLZ, M.; HARRE, J.:

A Model-Based Approach to Design Modular Plant Architectures.

In: Progress in virtual manufacturing systems.

Ed.: BLEY, Helmut.

Saarbrücken: CIRP College International pour l'Etude Scientifique des Techniques de

Production Mecanique, 2003, pp. 369-373.

(Proceedings of 36rd CIRP International Seminar on Manufacturing Systems)

SHIPLETT, R.:

Jellyfish statt Fischgräten.

In: Automobil-Produktion,

Landsberg, (2003)4, pp. 72-73.

ULRICH, K. T.; TUNG, K.:

Fundamentals of product modularity.

In: Issues in design-manufacture-integration.

Ed.: ANDIE, $S$.

New York, NY: Amercian society of mechanics engineers (ASME), 1991, pp. 73-79.

WESTKÄMPER, Engelbert; BRIEL, Ralf von :

Continuous improvement and participative factory planning by computer systems.

In: Annals of the CIRP,

Berne, 50(2001)1, pp. 347-356.

WIRTH, Siegfried; GÄSE, Thomas; GÜNTHER, Uwe:

Partizipative simulationsgestützte Layoutplanung.

In: wt Werkstattstechnik,

Düsseldorf, 91(2001)6, pp. 328-332. 
YOUNIS, M. A.; WAHAB, A. M.:

A CAPP Expert System for rotational components.

In: Computers and Industrial Engineering,

Amsterdam, 33(1997)3-4, pp. 509-512.

ZAEH, M. F.; WAGNER, W.:

Planning Minifactory Structures for the Close-to-Market Manufacture of Individualized

Products.

In: Proceedings of the MCPC 03: 2nd Interdisciplinary World Congress on Mass

Customization and Personalization 03.

Eds.: REICHWALD, R.; PILLER, F.; TSENG, $M$.

München: TU München, 2003. 